\title{
On the deposition rate in a high power pulsed magnetron sputtering discharge
}

\author{
J. Alami, Kostas Sarakinos, G. Mark and M. Wuttig
}

\section{Post Print}

N.B.: When citing this work, cite the original article.

Original Publication:

J. Alami, Kostas Sarakinos, G. Mark and M. Wuttig, On the deposition rate in a high power pulsed magnetron sputtering discharge, 2006, Applied Physics Letters, (89), 15, 154104. http://dx.doi.org/10.1063/1.2362575

Copyright: American Institute of Physics (AIP) http://www.aip.org/

Postprint available at: Linköping University Electronic Press http://urn.kb.se/resolve?urn=urn:nbn:se:liu:diva-71504 


\title{
On the deposition rate in a high power pulsed magnetron sputtering discharge
}

\author{
J. Alami ${ }^{\mathrm{a})}$ and K. Sarakinos \\ Institute of Physics (IA), RWTH Aachen University, 52056 Aachen, Germany \\ G. Mark \\ MELEC GmbH, 77833 Ottersweier, Germany
}

M. Wuttig

Institute of Physics (IA), RWTH Aachen University, 52056 Aachen, Germany

(Received 9 August 2006; accepted 29 August 2006; published online 13 October 2006)

\begin{abstract}
The effect of the high pulse current and the duty cycle on the deposition rate in high power pulsed magnetron sputtering (HPPMS) is investigated. Using a $\mathrm{Cr}$ target and the same average target current, deposition rates are compared to dc magnetron sputtering (dcMS) rates. It is found that for a peak target current density $I_{T_{\text {pd }}}$ of up to $570 \mathrm{~mA} \mathrm{~cm}^{-2}$, HPPMS and dcMS deposition rates are equal. For $I_{T_{p d}}>570 \mathrm{~mA} \mathrm{~cm}^{-2}$, optical emission spectroscopy shows a pronounced increase of the $\mathrm{Cr}^{+} / \mathrm{Cr}^{0}$ signal ratio. In addition, a loss of deposition rate, which is attributed to self-sputtering, is observed. () 2006 American Institute of Physics. [DOI: 10.1063/1.2362575]
\end{abstract}

High power pulsed magnetron sputtering ${ }^{1}$ (HPPMS) is a novel ionized physical vapor deposition technique ${ }^{2}$ that has been shown to result in superior film properties such as dense and smooth films, ${ }^{3}$ and good film adhesion. ${ }^{4}$ In HPPMS, power is supplied to the target (cathode) in unipolar pulses of high magnitude but low duty on time and frequency, resulting in a high degree of ionization of the sputtered material. ${ }^{2,5}$ Although HPPMS has been shown to be a promising technique, ${ }^{3,4,6-8}$ the deposition rate has been regarded as a major drawback. Rates varying between $20 \%$ and $80 \%$ of the rates achieved by dc magnetron sputtering (dcMS) were reported, for films deposited at a constant average power. ${ }^{9,10}$ Christie et al. ${ }^{9}$ proposed a model explaining this to be a result of the self-sputtering phenomenon that takes place due to the increased ionization in the discharge. ${ }^{7,11}$ In order to achieve the increased ionization, the target voltage is larger than in dcMS. As a consequence, depositions at a constant average power result in a lower average current $\left(I_{T_{a v}}\right)$ for the HPPMS depositions. Since deposition rate scales with the $I_{T_{\text {av }}}$, a constant average target current is utilized in order to compare deposition rates resulting from the two techniques. The aim of this work is to study the effect of the pulse on/off time configuration on the deposition rate of films grown by HPPMS at a constant average target current and to understand its correlation with the discharge characteristics.

High power unipolar pulses of a few hundreds of kilowatts were applied to a $\mathrm{Cr}$ target of $76 \mathrm{~mm}$ in diameter and $6 \mathrm{~mm}$ in thickness with duty on times ranging between $\sim 1 \%$ and $\sim 10 \%$. The power was supplied using an AE pinnacle dc power supply coupled to a SPIK 2000A pulsing unit from MELEC GmbH. ${ }^{12}$ The target current and voltage were measured using a LEM LA205-S current transducer and a LEM CV3-1500 voltage transducer, respectively, and were monitored in a TDS 2014 digital oscilloscope. Depending on the pulse configuration, peak target current densities ranging

\footnotetext{
a) Author to whom correspondence should be addressed; electronic mail:
} alami@physik.rwth-aachen.de from 90 to $2600 \mathrm{~mA} \mathrm{~cm}^{-2}$ were calculated. Cr films were grown at a distance of $70 \mathrm{~mm}$ from the target using an Ar gas of purity $99.999 \%$ and a pressure of $0.8 \mathrm{~Pa}$. Film thickness and consequently the deposition rates were determined with angstrom precision using $\mathrm{x}$-ray reflectometry. ${ }^{13}$ The ion flux to the growing films was quantified by measuring the ion saturation current at different deposition conditions, using a flat probe, while the plasma (electron) density was determined using a Langmuir probe. ${ }^{11}$ In order to investigate the changes in the plasma composition with changing deposition conditions, time resolved optical emission spectroscopy (OES) measurements were performed. A Mechelle 5000 spectrometer equipped with an intensified charge-coupled device camera for optimized signal count was used for the purpose. Light emission was collected using a fiber optic placed $30 \mathrm{~cm}$ from the target surface, at a $45^{\circ}$ angle. The OES measurements were carried out by measuring the emission intensity corresponding to the four wavelengths of 283.56, 301.73, 487.89, and $696.53 \mathrm{~nm}$, representing $\mathrm{Ar}^{+}$, $\mathrm{Ar}^{0}, \mathrm{Cr}^{+}$, and $\mathrm{Cr}^{0}$ species, ${ }^{14}$ respectively.

In order to investigate the deposition rate, depositions were performed for a number of average target current values using HPPMS and dcMS. The results (not shown here) demonstrated that the HPPMS deposition rate was equal to the dcMS deposition rate for low average current values but deviated from it for higher average current values. Further analysis showed that the deposition rate changed as a function of the target peak current, even when the average target current, $I_{T_{\mathrm{av}}}$, was kept constant. This indicated that the peak target current density, $I_{T_{\mathrm{pd}}}$, was the more appropriate parameter to use for deposition rate $\left(R_{d}\right)$ investigations. Figure 1 shows deposition rates for the two HPPMS pulse configurations 50/950 and 50/2450 (i.e., $50 \mu$ s on time and 950 and $2450 \mu$ s off times, respectively) and for the dc films. It is seen that a deviation from the dcMS rates (dotted lines) started at the same well defined $I_{T_{\mathrm{pd}}}$ value of $\sim 570 \mathrm{~mA} \mathrm{~cm}^{-2}$, for both pulse configurations.

In order to better understand the mechanisms responsible for the deposition rate loss, $I_{T_{\mathrm{pd}}}$ was investigated as a func- 


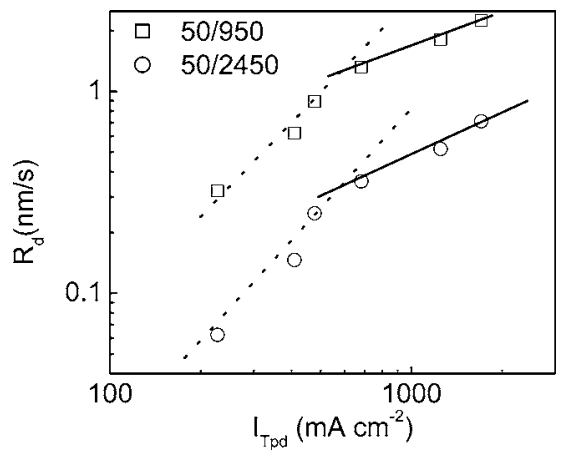

FIG. 1. Deposition rate $\left(R_{d}\right)$ vs the target current peak density $\left(I_{T_{\mathrm{pd}}}\right)$ for two HPPMS pulse configurations. Comparison with dc magnetron sputtering deposition rates (dotted lines) shows a rate decrease for both pulses starting at $I_{T_{\mathrm{pd}}}=570 \mathrm{~mA} \mathrm{~cm}^{-2}$.

tion of the target voltage $U_{T}$. Figure 2 presents $I_{T_{\mathrm{pd}}}$ vs $U_{T}$ in a log-log scale, for three pulse configurations, using the same pulse on time of $50 \mu \mathrm{s}$. The slopes of the $I_{T_{\mathrm{pd}}}-U_{T}$ curves changed at well defined positions (knees) corresponding to the $I_{T_{\mathrm{pd}}}$ values of $\sim 360, \sim 570$, and $\sim 1900 \mathrm{~mA} \mathrm{~cm}^{-2}$. The same knee positions were found when the pulse on time was changed to 25 and $100 \mu \mathrm{s}$ (not shown). A comparison between these finding and Fig. 1 shows that above $I_{T_{\mathrm{pd}}}$ $=570 \mathrm{~mA} \mathrm{~cm}{ }^{-2}$, i.e., above the second knee of the $I_{T_{\mathrm{pd}}}-U_{T}^{\mathrm{pd}}$ curve, $R_{d}$ falls below the dcMS value. This indicates that specific changes in the sputtering process occurred at this point, which will be further investigated in the following.

In dcMS, the relationship between the target current $I_{T}$ and the target voltage $U_{T}$ obeys the power law ${ }^{15} I_{T}=\alpha U_{T}^{\beta}$, with $\beta$ ranging between $5<\beta<15$. The corresponding value in our dcMS measurements was $\beta=8.5$, which is in accordance with literature. ${ }^{15}$ In HPPMS, a similar relation between the peak target current density and the target voltage is valid, i.e., $I_{T_{\mathrm{pd}}} \propto U_{T}^{\delta}$. $\delta$ was determined for different regions of the $I_{T_{\mathrm{pd}}}-U_{T}^{\mathrm{pd}}$ curves and for the different pulse configurations. It was found that $\delta \approx 18$ for $I_{T_{\mathrm{pd}}}$ lower than $360 \mathrm{~mA} \mathrm{~cm}^{-2}$ (part 1 in Fig. 2). This indicates that the discharge is dc-like with low plasma impedance, allowing $I_{T_{\mathrm{pd}}}$ to increase for a

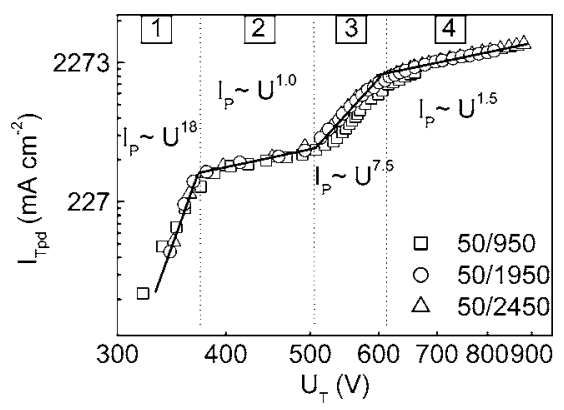

FIG. 2. Target peak current density $I_{T \text { pd }}$ vs target voltage $U_{T}$ for three pulse on/off time configurations. Changes in the relationship $I_{T_{\mathrm{pd}}} \sim U^{\delta}$ are seen at well defined $I_{T_{\mathrm{pd}}}$ values for all pulse configurations.

small increase of $U_{T}$. As $I_{T_{\mathrm{pd}}}$ was increased above $360 \mathrm{~mA} \mathrm{~cm}{ }^{-2}$ (from part 1 to part 2 in Fig. 2), the plasma became HPPMS like with ion flux densities at the substrate reaching 20-50 times dcMS flux densities, as determined by flat probe measurements. As a consequence, $\delta$ decreased from 18 to 1 . Similar observations were made by Ehiasarian et al., ${ }^{4}$ who proposed this to be the effect of the loss of magnetron confinement. However, in our experiments, the $\delta$ value increased further when $I_{T_{\mathrm{pd}}}$ was increased (part 3), which suggests that the explanation for the slope change at this stage must lie otherwise. In order to unravel the origin of the change of the $I_{T}-U_{T}$ slope, time resolved optical emission analysis for different plasma conditions was performed.

The OESs are displayed in Fig. 3, where $I_{T}$ is increased as we move from Figs. 3(a)-3(d). In Fig. 3(a), the pulse configuration with a $50 \mu \mathrm{s}$ on time and a $950 \mu \mathrm{s}$ off time $(50 / 950)$, and an average current $I_{T_{\mathrm{av}}}=0.35 \mathrm{~A}$ was used. In Fig. 3(b), the pulse off time was increased to $2450 \mu$ s, i.e., the duty cycle was decreased from $\sim 5 \%$ to $\sim 2 \%$, while $I_{T_{\mathrm{av}}}$ was kept at $0.35 \mathrm{~A}$. As a consequence, $I_{T_{\mathrm{pd}}}$ increased from 270 to $500 \mathrm{~mA} \mathrm{~cm}^{-2}$. In Figs. 3(c) and 3(d), the same pulse configuration $(50 / 2450)$ was used, while the average target currents $I_{T_{\mathrm{av}}}$ was increased to $1 \mathrm{~A}\left(I_{T_{\mathrm{pd}}}=1600 \mathrm{~mA} \mathrm{~cm}^{-2}\right)$ and $2 \mathrm{~A}\left(I_{T_{\mathrm{pd}}}=2800 \mathrm{~mA} \mathrm{~cm}^{-2}\right)$, respectively. Figure 3(a) shows

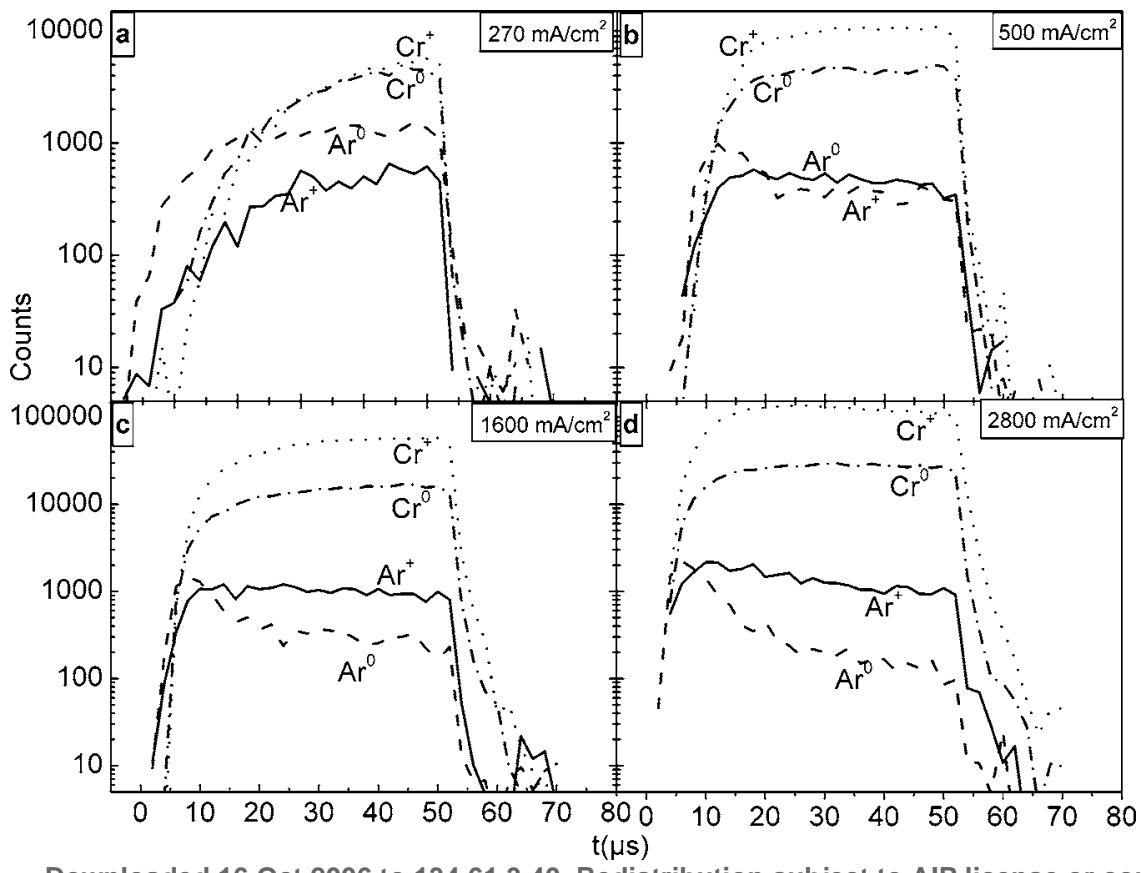

FIG. 3. Temporal optical emission spectroscopy for four pulse on/offtime configurations during high power pulsed magnetron sputtering. The peak target current density increases from 270 in (a) to 500, 1600, and $2800 \mathrm{~mA} \mathrm{~cm}^{-2}$ (b), (c), and (d), respectively, resulting in an increase of the $\mathrm{Cr}^{+} / \mathrm{Cr}^{0}$ ratio, and indicating an increased ionization degree. $\mathrm{Ar}^{+}$and $\mathrm{Ar}^{0}$ emission intensities decrease as a result of rarefaction in (b)-(d).

Downloaded 16 Oct 2006 to 134.61.3.40. Redistribution subject to AIP license or copyright, see http://apl.aip.org/apl/copyright.jsp 
that the intensities of the $\mathrm{Ar}^{+}$and $\mathrm{Ar}^{0}$ lines increased during the pulse on time. However, as $I_{T_{\mathrm{pd}}}$ increased [Figs. 3(b)-3(d)], $\mathrm{Ar}^{+}$and $\mathrm{Ar}^{0}$ signal intensities increased only at the beginning of the pulse $(t<10 \mu \mathrm{s})$ but decreased for $t$ $>10 \mu \mathrm{s}$, most notably for $\mathrm{Ar}^{0}$. This is an indication of the depletion of the Ar species (rarefaction ${ }^{15}$ ), especially neutrals, from the area close to the target surface. Rossnagel and Kaufman ${ }^{15}$ showed that during dc sputtering, the gas in front of the target is heated by collisions with the energetic sputtered atoms from the target, resulting in rarefaction. In HPPMS, rarefaction is more pronounced, since the instantaneous sputtering rate during the pulse on time $(50 \mu \mathrm{s})$ is one to three orders of magnitude higher than the dc sputtering rate. This is estimated from the magnitude of $I_{T \mathrm{pd}}$ which is one to three orders of magnitude higher than the target current density in dcMS. Furthermore, $U_{T}$ is generally higher in HPPMS than in dcMS resulting in particles' energy distributions with broader high energy parts and higher average energy, as was shown by Lattemann et al. ${ }^{16}$ As a result, the rarefaction is enhanced further, which causes an increase of the plasma impedance and consequently an increase of the target voltage. This is illustrated in Fig. 2, part 2, where it is seen that the $\delta$ value in the $I_{T \text { pd }}-U_{T}$ curve decreases to $\delta$ $\sim 1$. Analysis of the corresponding regions in Fig. 1 shows that the rarefaction of the gas species does not affect the deposition rate.

Numeric integration over the emission curves in Fig. 3 showed that when $I_{T_{\mathrm{pd}}}$ was increased by two-, six-, and tenfolds (parts 2, 3, and 4, respectively), the $\mathrm{Cr}^{0}$ emission count increased by $1.5-, 6-$, and 12 -folds, while the $\mathrm{Cr}^{+}$emission intensity increased by $33-, 150-$, and 400 -folds, respectively. A substantial increase of the ionization is, thus, demonstrated notably for parts 3 and 4 . Ion saturation measurements revealed that for HPPMS with $I_{T_{\mathrm{pd}}}=700 \mathrm{~mA} \mathrm{~cm}^{-2}$, an ion current of approximately two orders of magnitude higher than in a dcMS discharge was obtained. The increased ion flux is a result of the increased electron density, $n_{e}$, which was found to be $2.3 \times 10^{17} \mathrm{~m}^{-3}$ in the substrate vicinity, which is approximately two orders of magnitude higher than in conventional dcMS. The substantial increase of the plasma charge density causes a decrease of the plasma impedance, and consequently, an increase of the exponent $\delta \sim 7.5$, as seen in part 3 of Fig. 2. Furthermore, it is seen in Fig. 1 that deposition rate decreases in this region $\left(I_{T_{\mathrm{pd}}}>570 \mathrm{~mA} \mathrm{~cm}^{-2}\right)$. The mechanisms behind the deposition rate loss in HPPMS have been studied by other workers ${ }^{9,10}$ and are shown to be a result of self-sputtering (i.e., Cr performing the sputtering rather than Ar).
Finally, as the $I_{T_{\mathrm{pd}}}$ increased above $1900 \mathrm{~mA} \mathrm{~cm}{ }^{-2}$, the target voltage increased $\left(U_{T}>640 \mathrm{~V}\right.$ in Fig. 2, part 4). As a result, the magnetic field was too weak to keep the highly energetic plasma particles in the vicinity of the target, leading to a loss of plasma confinement and an increase of plasma impedance as illustrated by the drop in the $\delta$ value $(\delta \approx 1.5)$ in Fig. 2.

In conclusion, it was shown that deposition rates equal to values achieved by dcMS are obtainable by high power pulsed magnetron sputtering, up to peak target current densities of $570 \mathrm{~mA} \mathrm{~cm}^{-2}$. For $I_{T_{\mathrm{pd}}}<360 \mathrm{~mA} \mathrm{~cm}^{-2}$, the plasma was dc-like. However, as $I_{T_{\mathrm{pd}}}$ was increased above $360 \mathrm{~mA} \mathrm{~cm}^{-2}$, depletion of species in front of the target (rarefaction) was observed, accompanied by an increase of the discharge impedance. A further increase of the $I_{T_{\mathrm{pd}}}$ above $570 \mathrm{~mA} \mathrm{~cm}^{-2}$ resulted in a substantial increase in ionization accompanied by a decrease of the deposition rate, due to self-sputtering. Finally, for $I_{T_{\mathrm{pd}}}>1900 \mathrm{~mA} \mathrm{~cm}{ }^{-2}$, loss of the magnetic confinement was observed.

This work was supported by the Deutsche Forschungsgemeinschaft (Wu 243/13).

${ }^{1}$ The deposition technique HPPMS is also known as HIPIMS.

${ }^{2}$ V. Kouznetsov, K. Macák, J. M. Schneider, U. Helmersson, and I. Petrov, Surf. Coat. Technol. 122, 290 (1999).

${ }^{3}$ J. Alami, P. O. Å. Persson, J. Böhlmark, J. T. Gudmundsson, D. Music, and U. Helmersson, J. Vac. Sci. Technol. A 23, 278 (2005).

${ }^{4}$ A. P. Ehiasarian, R. New, W.-D. Münz, L. Hultman, U. Helmersson, and V. Kouznetsov, Vacuum 65, 147 (2002).

${ }^{5}$ S. Konstantinidis, A. Ricad, M. Ganciu, J. P. Dauchot, C. Ranea, and M. Hecq, J. Appl. Phys. 95, 2900 (2004).

${ }^{6}$ W. D. Sproul, D. J. Christie, and D. C. Carter, 47th Annual Technical Conference Proceedings, Society of Vacuum Coaters (2004), p. 96.

${ }^{7}$ S. Konstantinidis, J. P. Dauchot, M. Ganciu, and M. Hecq, Appl. Phys. Lett. 88, 021502 (2006).

${ }^{8}$ J. Alami, P. Eklund, J. Emmerlich, O. Wilhelmsson, U. Jansson, H. Högberg, L. Hultman, and U. Helmersson, Thin Solid Films (to be published).

${ }^{9}$ D. J. Christie, J. Vac. Sci. Technol. A 23, 330 (2005).

${ }^{10}$ U. Helmersson, M. Lattemann, J. Bohlmark, A. P. Ehiasarian, and J. T. Gudmundsson, Thin Solid Films 513, 1 (2006).

${ }^{11}$ J. T. Gudmundsson, J. Alami, and U. Helmersson, Appl. Phys. Lett. 78, 3427 (2001).

${ }^{12}$ MELEC GmbH, U.S. Patent No. 6,735,099 B2 (17 April 2001).

${ }^{13} \mathrm{H}$. Weis, T. Müggenburg, P. Grosse, L. Herlitze, I. Friedrich, and M. Wuttig, Thin Solid Films 351, 184 (1999).

${ }^{14}$ Handbook of Chemistry and Physics (CRC, Boca Raton, FL, 1988), 69th ed., pp. E212-E228.

${ }^{15}$ S. M. Rossnagel, and H. R. Kaufman, J. Vac. Sci. Technol. A 6, 223 (1988).

${ }^{16}$ M. Lattemann, A. P. Ehiasarian, J. Bohlmark, P. Å. O. Persson, and U. Helmersson, Surf. Coat. Technol. 200, 6495 (2006). 